\title{
Informe das atividades desenvolvidas pelo Grupo de Antropologia Visual da USP
}

O GRAVI (Grupo de Antropologia Visual), ligado ao do Departamento de Antropologia da USP, nasceu em 1995 com o objetivo de reunir pesquisadores interessados em um maior conhecimento desta área da Antropologia e nas possibilidades de análise e produção de imagens a partir de uma perspectiva antropológica. Integram o grupo doutores e bolsistas de Iniciação Científica, mestrado, doutorado e pós doutorado em Antropologia. O GRAVI reúne-se com regularidade no Laboratório de Imagem e Som em Antropologia (LISA-USP), organizando seminários para discussão de textos, filmes, fotos e pesquisas em andamento, workshops de formação dos pesquisadores em técnicas e linguagens ligadas ao campo da produção e análise de imagens e sons e busca o constante intercâmbio com pesquisadores da comunidade acadêmica dentro e fora do Brasil.

No Brasil o GRAVI contribuiu para fortalecer uma rede de pesquisadores no campo da antropologia audiovisual, estreitando laços especialmente com os seguintes núcleos e grupos de pesquisas: BIEV - Banco de Imagens e Efeitos Visuais (PPGAS-UFRGS); Laboratório de Antropologia Visual (PPGA-UFPE); LEPPAIS - Laboratório de Ensino, Pesquisa e Produção em Antropologia da Imagem e do Som (Universidade Federal de Pelotas); NAI - Núcleo de Antropologia e Imagem (Depto. Ciências Sociais- UERJ); NAVI - Núcleo de Antropologia Visual e Estudos da Imagem - (UFSC); NAVISUAL - Núcleo de Antropologia Visual (PPGAS-UFRGS); NEXTimagem - Núcleo de Experimentaçóes em Etnografia e Imagem (PPGSA-UFRJ); INARRA - Imagens, Narrati- vas e práticas Culturais (PPCIS-UERJ); NAVI - Núcleo de Antropologia Visual (PPGSC-UFAM); VISURB - Grupo de pesquisas Visuais e Urbanas (UNIFESP).

Ao longo dos anos o GRAVI estabeleceu também parcerias com integrantes de núcleos ou grupos de pesquisa internacionais, dentre os quais se destacam: Granada Centre for Visual Anthropology, Inglaterra; École de Hautes Études, França, Australia National University, Austrália; Museu de Etnologia de Berlim, Alemanha; Museu de Etnologia e ISCTE, Portugal; Laboratório de Antropologia Visual da Universidade Aberta, Portugal; Contro-Sguardi, Itália; New York University e University of California, nos Estados Unidos, Centre Interuniversitaire d'Études et de Recherches Autochtones (CIERA), Université Laval e Université de Québec à Chicoutimi, no Canadá.

Dentre os pesquisadores brasileiros com quem mantemos parcerias destacam-se Ana Luiza Carvalho da Rocha, Carmen Rial, Clarice Peixoto, Cornelia Eckert, Etienne Samain, Fernando de Tacca, João Martinho de Mendonça, Renato Athias, além de pesquisadores da ECA-USP, como Cristian Borges, Dora Mourão, Esther Hamburguer, Henri Gervaiseau, Ismail Xavier, João Musa, Marília Franco, Roberto Moreira, Sergio Bairon. Vários pesquisadores estrangeiros apresentaram cursos e palestras no LISA, dentre eles Catarina Alves Costa, David MacDougall, Dorothy Hénault, Gary Kildea, Jean Rouch, Joachim Wossidlo, Johannes Sjoberg, José da Silva Ribeiro, Kazadi Wa Mukuna, Marc Henri-Piault, Paul Henley, Pierre Jordan, Silvain Maresca, Trinh Minh-ha. 
346 | Informe das ATIVIDAdes desenVolvidas PELo Grupo de ANTropologia Visual da USP

A maturidade do grupo foi conquistada ao longo dos anos com a elaboração de pesquisas que levaram a mestrados, doutorados, pós-doutorados, com o apoio fundamental da FAPESP, que igualmente financiou publicaçôes e a participação de seus membros em congressos, colóquios e seminários nacionais e internacionais. As pesquisas foram realizadas ao longo de 3 projetos temáticos, todos com financiamento FAPESP e com a duraçáo de 4 anos cada um deles: "Imagem em foco nas Ciências Sociais"; "Alteridade, Expressóes Culturais do Mundo Sensível e Construçóes da Realidade" e "A Experiência do Filme na Antropologia", todos coordenados pela Profa. Sylvia Caiuby Novaes.

O primeiro projeto (1998-2002) pretendeu demonstrar a pertinência da análise e produção da imagem por parte de pesquisadores ligados às Ciências Sociais, que pouco, até então, tinham se dedicado a esta temática. Os projetos propostos agruparam-se em três grandes blocos: 1) pesquisas que tiveram como resultado a produção da imagem em vídeo, fotografia e CD-ROM; 2) pesquisas centradas na questão da representação em imagens fílmicas e fotográficas; 3) pesquisas que permitiram a criação de metodologia adequada para a catalogação de imagens e criação de bancos de dados.

O segundo projeto (2003-2008) priorizou a investigação de diferentes vias de acesso ao tema da alteridade, sempre tendo em vista as mediaçôes do olhar lançado ao outro. A primeira linha deste segundo projeto temático, "Traduçóes da Alteridade", estimulada pelas reflexões levantadas por Arjun Appadurai, Georges Marcus, James Clifford, Marcus Fischer, procurava entender os modos pelos quais se têm construído a alteridade nos relatos textuais, fílmicos, videográficos ou na web. Investigamos o que há de específico em cada uma dessas linguagens e, ao mesmo tempo, quais são os espaços de intersecção entre elas. A se- gunda linha, "Expressões Culturais do Mundo Sensível", procurou abordar a questâo do outro e de seu fazer artístico de um ponto-de-vista êmico, enfocando os processos subjacentes a este fazer num contexto cultural específico. A terceira perspectiva, "Linguagens e Narrativas", procurou analisar estes discursos e produzi-los, buscando a compreensão da relação entre real e construção do real estabelecida por eles.

Finalmente o terceiro projeto temático (2010-2014), ainda em curso, centra-se em duas vertentes. Uma delas aborda as relaçôes entre a Antropologia, a Fotografia e o Cinema, que se iniciam nos primórdios da invenção da máquina fotográfica, do cinematógrafo e da própria disciplina antropológica. Se os encontros iniciais entre antropologia e essas novas técnicas de reprodução da imagem marcam as primeiras descobertas das possibilidades de contato e contágio, cem anos mais tarde as tensóes são tantas quanto as efetivas aproximações entre as áreas. Um dos objetivos deste projeto é, pois, refletir sobre as experiências de apropriação mútua entre elas a partir da teoria antropológica, além de experimentar as possibilidades deste encontro, por meio da realização de filmes etnográficos e ensaios fotográficos. A segunda vertente está mais ligada ao que se convencionou chamar de Antropologia da Arte. Trata-se, nesta segunda linha de pesquisa, de perceber a realização audiovisual no âmbito da produção de conhecimento antropológico como expressão de um diálogo entre a teoria antropológica clássica e outros campos da própria antropologia como o da antropologia da arte e a etnoestética, bem como com campos vizinhos como os das artes visuais e cênicas.

Além de livros e diversos artigos publicados em livros e periódicos nacionais e internacionais, os pesquisadores do GRAVI publicaram algumas coletâneas que resultaram das pesqui- 
sas dos dois primeiros temáticos finalizados: Escrituras da Imagem (Edusp, 2004) e Imagem-Conhecimento (Papirus, 2009).

Escrituras da Imagem resulta do primeiro projeto temático desenvolvido pelos pesquisadores do GRAVI. Reúne reflexóes sobre a imagem, em especial a linguagem do cinema, a partir das ciências sociais e ensaios fotográficos, comentados por seus autores e por pesquisadores convidados.

Imagem-conhecimento resulta do encontro de pesquisadores do GRAVI com colegas estrangeiros interessados em discutir as aproximaçóes entre as Ciências Sociais e outros universos como o das imagens, dos sons e das artes visuais. Tal encontro deu-se durante o Simpósio Internacional "Tradução e Percepção - Ciências Sociais em Diálogo”, realizado em maio de 2006 na Universidade de São Paulo. Este foi um momento de debate contemplando um amplo espectro temático a partir de diferentes tradiçóes teóricas que lidam com as questóes centrais discutidas no encontro. O livro relata experiências de pesquisa e reflexóes diversas que trazem como elo o movimento de repensar estéticas, métodos e formas de construir o conhecimento.

Cobrindo várias regióes do Brasil e trabalhando na intersecção entre antropologia, cinema, fotografia, teatro, arte e novas mídias, os pesquisadores do GRAVI desenvolvem investigações sobre diferentes temáticas: corpo, gênero, religião, ritual, trabalho, periferia, memória, representação, música, teatro, artes visuais, mídias colaborativas, identidade, entre outras. O GRAVI reúne atualmente 32 integrantes, entre alunos de graduação, mestrandos, mestres, doutorandos, doutores, pós-doutorandos e pós-doutores. Em uma política de formação acadêmica contínua, alguns de seus membros entraram como alunos e tornaram-se professores na própria Universidade de São Paulo e em outras instituições como a Universidade Federal do Estado de São Paulo, Universidade Federal Fluminense, Universidade Estadual do Norte Fluminense, Universidade Estadual Paulista, Universidade Federal de Santa Catarina e University of East Anglia (UK).

Além de projetos de pesquisas, o GRAVI promove no LISA seminários abertos no campo da Antropologia Visual, convidando pesquisadores e professores para apresentar seus trabalhos, permitindo um diálogo interdisciplinar dentro da USP e fora dela. Em sua trajetória, vem estreitando os laços com cineastas, fotógrafos, historiadores, sociólogos, museólogos e demais profissionais da comunicação e da arte. Finalmente, muitos integrantes do GRAVI prestam assessoria antropológica em projetos visuais e sonoros (exposições diversas, mostras de filmes, produçóes fílmicas, prêmios de fotografia e vídeos, mapeamentos multimídia), além de coordenarem oficinas nestas duas áreas e produzirem filmes e materiais fotográficos para exposiçōes.

Um dos principais resultados das pesquisas realizadas junto ao GRAVI é a produção de filmes etnográficos que pode, atualmente, ser consultada no Vimeo do LISA (www.vimeo. com/lisausp) com boa parte dos filmes na íntegra e em boa definição. Dentre a nossa produção, cabe destacar alguns que foram premiados e/ou agraciados com editais: Jean Rouch, subvertendo fronteiras (2000), Ponteio - jogaram a viola no mundo, mas fui lá no fundo buscar (2001), O Arco e a Lira (2002), Ritual da Vida (2005), Em (si) mesma (2006), Pelas Marginais (2007), Cinema de Quebrada (2008), Lá do Leste (2010).

Website: www.lisa.usp.br/gravi

Coordenadora: Profa. Sylvia Caiuby Novaes 
Vice Coordenadora: Profa. Dra. Rose Joon Ho Kim, Kelen Pessuto, Magda dos SanSatiko Gitirana Hikiji

Pesquisadores doutores: Ana Lucia Ferraz tos Ribeiro, Nadja Woczkosky Marin, Vitor Pinheiro Grunvald.

(UFF), Andrea C. M. Marques Barbosa (UNIFESP), Aristóteles Barcelos Neto (University of East Anglia, UK), Edgar Teodoro

Pesquisadores Mestres: Alexandre Kishimoto, Diana Paola Gómez Mateus, Maíra Santi Buhler.

da Cunha (UNESP), Ewelter de Siqueira e Rocha (UECE), Francirosy C. B. Ferreira (USP), Lilian Sagio Cezar (UENF), Miriam L. Moreira Leite (USP), Paula Morgado Dias Lopes (USP), Priscilla Barrak Ermel, Renato Sztutman (USP), Yara Schreiber Dines (USP).

Pesquisadores doutorandos: Alice Martins Villela Pinto, Andrea de Moraes Cavalheiro,

Pesquisadores mestrandos: André Luís Lopes Neves, Bruna Nunes da Costa, Eduardo da Silva Garcia, Guilherme Kasuo L. Yokote, Paulo Menotti Del Picchia, Renato Jacques de Brito Veiga, Victor Eiji Issa.

Pesquisadores graduandos: Danilo Bezerra de Souza, Gabriel Campos Ferreira, Isadora Moreira Martins de Souza. 